\title{
Temperature Rise during Primer, Adhesive, and Composite Resin Photopolymerization of a Low-Shrinkage Composite Resin under Caries-Like Dentin Lesions
}

\author{
Sayed-Mostafa Mousavinasab, ${ }^{1}$ Maryam Khoroushi, ${ }^{2}$ and Mohammadreza Moharreri ${ }^{3}$ \\ ${ }^{1}$ Torabinejad Dental Research Center and Department of Operative Dentistry, School of Dentistry, \\ Isfahan University of Medical Sciences, Isfahan 81746-73461, Iran \\ ${ }^{2}$ Dental Materials Research Center and Department of Operative Dentistry, School of Dentistry, \\ Isfahan University of Medical Sciences, Isfahan 81746-73461, Iran \\ ${ }^{3}$ Department of Operative Dentistry, School of Dentistry, Isfahan University of Medical Sciences, Isfahan 81746-73461, Iran
}

Correspondence should be addressed to Maryam Khoroushi, khoroushi@dnt.mui.ac.ir

Received 18 October 2012; Accepted 26 November 2012

Academic Editors: H. S. Cardash, G. V. Kulkarni, and M. Tanomaru-Filho

Copyright ( $) 2012$ Sayed-Mostafa Mousavinasab et al. This is an open access article distributed under the Creative Commons Attribution License, which permits unrestricted use, distribution, and reproduction in any medium, provided the original work is properly cited.

\begin{abstract}
Objective. This study evaluated temperature rise of low-shrinkage (LS) self-etch primer (P), LS self-etch adhesive (A), and P90 silorane-based composite resin systems, photopolymerized under normal and artificially demineralized dentin. Methods. Forty $1.5 \mathrm{~mm}$-thick dentin discs were prepared from sound human molars, half of which were demineralized. Temperature rise was measured during photopolymerization using a K-type thermocouple under the discs: $10 \mathrm{~s}$ and $40 \mathrm{~s}$ irradiation of the discs (controls/groups 1 and 2); $10 \mathrm{~s}$ irradiation of primer (P), $10 \mathrm{~s}$ irradiation of adhesive (A), $40 \mathrm{~s}$ irradiation of P90 without $\mathrm{P}$ and $\mathrm{A}$, and $40 \mathrm{~s}$ irradiation of $\mathrm{P} 90$ with $\mathrm{P}$ and A (groups 3 to 6, resp.). The samples were photopolymerized using an LED unit under $550 \mathrm{~mW} / \mathrm{cm}^{2}$ light intensity. Data was analyzed using repeated measures ANOVA and paired-sample $t$-test $(\alpha=0.05)$. Results. There were no significant differences in temperature rise means between the two dentin samples for each irradiation duration $(P>0.0001)$, with significant differences between the two irradiation durations $(P>0.0001)$. Temperature rise measured with $40 \mathrm{~s}$ irradiation was significantly higher than that of $10 \mathrm{~s}$ duration for undemineralized and demineralized dentin $P<0.0001)$. Conclusions. Light polymerization of P90 low-shrinkage composite resin resulted in temperature rise approaching threshold value under artificially demineralized and undemineralized dentin.
\end{abstract}

\section{Introduction}

Exothermic photopolymerization reaction of resin-based restorative materials and the heat produced by light-curing units (LCUs) might irritate the pulp due to an increase in temperature in the tooth cavity $[1,2]$. Various factors, including the intensity of the light [3], the chemical composition of the restorative material $[4,5]$, heat conduction properties of composite resins [6], the depth of the cavity or the thickness of the restoration $[6,7]$, and irradiation duration $[8,9]$, might influence the extent of temperature rise during photopolymerization.

Studies have shown that the heat generated during restorative procedures might have a detrimental effect on dental pulp. There is still controversy over the $5.5^{\circ} \mathrm{C}$ threshold temperature rise for irreversible changes in the dental pulp $[10,11]$.

Dentin has been reported to have a low thermal conductivity; however, the risk of irreversible pulp damage is greater in deep cavities with minimal residual dentin thickness, in which there is a concomitant increase in tubular surface area [12]. A large number of in vitro studies have been carried out to determine temperature rise during light-curing procedures of resin-based restorative materials; these studies have predominantly used ground or non-carious dentin substrates [13-16]. However, in most clinical situations noncarious dentin is not encountered [17], and carious dentin is generally restored. Carious dentin characteristically consists of infected and affected layers; the affected dentin layer is not usually removed during restorative procedures $[18,19]$. 
Therefore, a layer of caries-affected dentin remains on the cavity floor after removal of a carious lesion and preparation of the cavity for an adhesive restorative procedure $[19,20]$.

Only a limited number of studies have been carried out in an attempt to evaluate temperature rise during the photopolymerization procedures of resin-based restorative materials beneath sound and carious dentin [21, 22]. Fanbunda and colleague [21] reported a significantly higher thermal conductivity for carious dentin compared to sound dentin, that is, carious dentin has less capacity to form a thermal barrier against heat. Tosun et al. [22] compared the temperature rise under sound and caries-affected primary tooth dentin during photopolymerization of two adhesives, including AdheSE Bond and One Step Plus, and two resinbased restorative materials, including Compoglass $\mathrm{F}$ and Aelite LS. They reported a temperature rise beyond $5.5^{\circ} \mathrm{C}$ threshold during photopolymerization of adhesive materials under caries-affected primary tooth dentin. Moreover, adhesive systems induced a higher temperature rise during photopolymerization in comparison to resin-based restorative materials. The structural differences between sound and caries-affected primary tooth dentin had an influence on temperature rise during photopolymerization of resin-based materials.

Filtek LS (3M ESPE, St. Paul, MN, USA), a new siloranebased $\mathrm{RBC}$ resin, has been developed in an attempt to minimize polymerization shrinkage. Its siloxane oxirane resin molecule is light-cured through a cationic ring-opening reaction after an interaction between camphorquinone, iodonium salts, and electron donors. The manufacturer has recommended that the light-curing procedure should exceed 20 seconds because this is the minimum duration of time for the activation of the initiator [23]. Furthermore, based on manufacturer's instructions, there are separate $10 \mathrm{~s}$ photopolymerization steps for the LS primer and LS adhesive in this system (Table 1) [23].

Optical pyrometry studies have revealed that cationic ring-opening polymerization of oxiranes is highly exothermic, with temperature increases from the ambient temperature to $>100^{\circ} \mathrm{C}$ in a few seconds [24]. It has been postulated that the amount of heat generated during cationic photopolymerization has a direct relationship with the number of photogenerated initiating species in the system [25].

The aim of this in vitro study was to evaluate temperature fluctuations under sound and artificially demineralized dentin during light polymerization of the LS self-etch primer $(\mathrm{P})$ and adhesive $(\mathrm{A})$ and the silorane-based composite resin (P90). The null hypothesis was that the temperature rise induced by each photopolymerization step of LS primer, LS bond and LS composite under undemineralized dentin (control) would not be different from that under artificially demineralized dentin.

\section{Materials and Methods}

Table 1 presents the chemical compositions and instructions for use of Filtek P90 primer, adhesive, and restorative material used in the present study. Shade A3 of the material was photopolymerized using Bluephase light source (Bluephase, Ivoclar Vivadent, Schaan, Liechtenstein) at $550 \mathrm{~mW} / \mathrm{cm}^{2}$. The light output of the polymerizing unit was checked before each procedure using a radiometer (Curing Radiometer, Kerr, Orange, CA, USA).

2.1. Specimen Preparation. The research protocol was approved by the Human Ethics Committee of the School of Dentistry, Isfahan University of Medical Sciences. Forty extracted sound human third molars were used in the present study within three months of extraction.

Dentin discs measuring $1.5 \mathrm{~mm}$ in thickness were prepared from the deep dentin layers of 40 extracted third molars. First, each tooth was mounted in epoxy resin (Triplex Acryl, Ivoclar Vivadent, Schaan, Liechtenstein); then sections were prepared parallel to the long axis of each tooth with a low-speed diamond saw (Servocut, M-300, Switzerland) under copious water irrigation. Perpendicular cuts were made to prepare dentin disks measuring $1.5 \mathrm{~mm}$ (Figure 1). The surfaces of the samples were wet-ground using 320 - and 400-grit SIC abrasive papers under water cooling to prepare flat dentin surfaces.

Half of the samples were placed in a demineralizing solution to prepare artificially demineralized dentin samples resembling caries-like dentin lesions; each dentin sample was placed in $20 \mathrm{~mL}$ of a demineralizing solution for 48 hours at $23^{\circ} \mathrm{C}$ [26]. The chemical composition of the solution was as follows: $\mathrm{CaCl}_{2}, 0.002 \mathrm{M} / \mathrm{L} ; \mathrm{KH}_{3} \mathrm{PO}_{4}, 0.002 \mathrm{M} / \mathrm{L}$; glacial acetic acid, $0.002 \mathrm{M} / \mathrm{L}$, with a $\mathrm{pH}$ value of 4.3 [26]. Finally, the samples were stored in water to prevent dehydration until used for the purpose of the study.

2.2. Temperature Measurements. The ambient temperature was $23 \pm 1^{\circ} \mathrm{C}$; the temperature of a 40 s irradiation procedure of the unit, without any dentin or restorative material samples, was recorded at $18.19^{\circ} \mathrm{C}$. Temperature rise in the dentin samples was measured prior to photopolymerization procedures using $10 \mathrm{~s}$ and $40 \mathrm{~s}$ test runs so that it would be possible to assess whether structural variables of dentin samples would affect temperature variations.

The mean of temperature rise was measured during $10 \mathrm{~s}$ (group 1) and $40 \mathrm{~s}$ (group 2) irradiation durations with the LED light-curing unit under the undemineralized and demineralized dentin samples.

In order to measure temperature rise during photopolymerization of the LS system primer (LS Primer, 3M ESPE) (groups 3), the material was applied on undemineralized and demineralized dentin samples and cured according to manufacturers' instructions (Table 1). The same steps were followed for the LS system adhesive (groups 4) (Figure 1), that is, the LS system adhesive was applied on the dentin samples and light-cured LS primer and photopolymerized for 10 seconds. Temperature variations were recorded for all the demineralized and undemineralized dentin samples $(n=10)$ (Figure 1).

After photopolymerization of the primer and adhesive resin, the temperature rise was measured. Subsequently, 
TABLE 1: Materials used in the study, their compositions and sources.

\begin{tabular}{llc}
\hline Material & Composition & Manufacturer \\
\hline \multirow{2}{*}{ LS system adhesive self-etch primer (pH: 2.7) } & $\begin{array}{l}\text { Phosphorylated methacrylates, Vitrebond copolymer, } \\
\text { bis-GMA, HEMA, water, ethanol, silane-treated silica }\end{array}$ & 3M ESPE, St. Paul, MN, \\
& $\begin{array}{l}\text { filler, initiators, stabilizers } \\
\text { USA }\end{array}$ & Hydrophobic dimethacrylate, phosphorylated \\
LS system adhesive self-etch bond & $\begin{array}{l}\text { methacrylates, TEGDMA, silane-treated silica filler, } \\
\text { initiators, stabilizers }\end{array}$ & $3 \mathrm{M}$ ESPE, St. Paul, MN, \\
Filtek LS & $\begin{array}{l}\text { Silorane resin, initiating system, quartz filler, yttrium } \\
\text { fluoride, stabilizers, pigments }\end{array}$ & $3 \mathrm{M}$ ESPE, St. Paul, \\
& MN, USA
\end{tabular}

bis-GMA: Bisphenol A glycol dimethacrylate; HEMA: 2-hydroxyethyl methacrylate; TEGDMA: triethyleneglycol dimethacrylate.

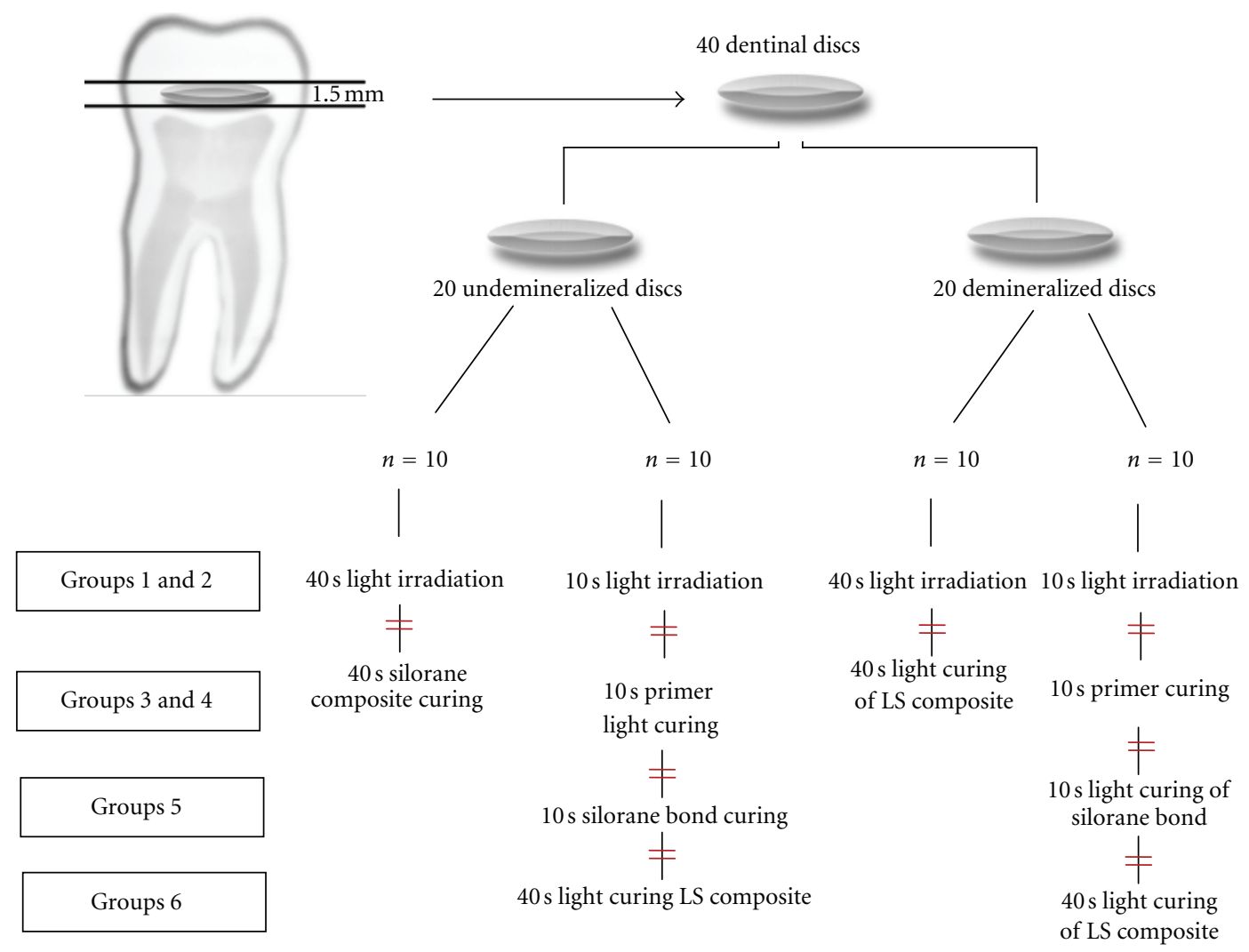

FIGURE 1: Schematic view of the different steps for preparation of the dentinal discs and different groups. Signs "=" show the steps which the temperature rise under the each disc has been recorded using thermocouple.

the central cylinder was filled with $2 \mathrm{~mm}$ of the Filtek P90 composite resin and light-cured for 40 seconds (Table 1) (groups 5). Furthermore, for 10 undemineralized and 10 demineralized dentin samples, a $2 \mathrm{~mm}$ thick sample of Filtek LS, without primer and adhesive, was light-cured for $40 \mathrm{~s}$; then temperature rise was measured beneath demineralized and undemineralized dentin samples (groups 6).

For all the study groups, temperature rise was measured beneath demineralized and undemineralized dentin samples. To this end, a Teflon mold was used to support the dentin sample and the resin restorative material (Figure 2). Tip of the light conductor of the curing unit was placed on the LS primer and adhesive with a 2-mm distance in between; no space was left between the LS resin materials and the tip with the use of a celluloid matrix. A K-type thermocouple wire with a diameter of $0.1 \mathrm{~cm}$ (Standard, ST-8891E, Taiwan) was connected to a data logger (Standard, ST-8891E, Taiwan) during the light-curing procedure of the LS primer, LS adhesive and Filtek LS composite resin restorative material (Figure 2).

Sampling rate of data logger was adjusted at one sample per second, starting with light-curing for 120 seconds until the temperature began to decrease. Data, presented in graphic forms, was monitored real-time and recorded in a computer.

Light output of the curing unit was evaluated prior to each procedure using an LED radiometer (LED Radiometer, Kerr, Orange, CA, USA). The intensity of light during the test 


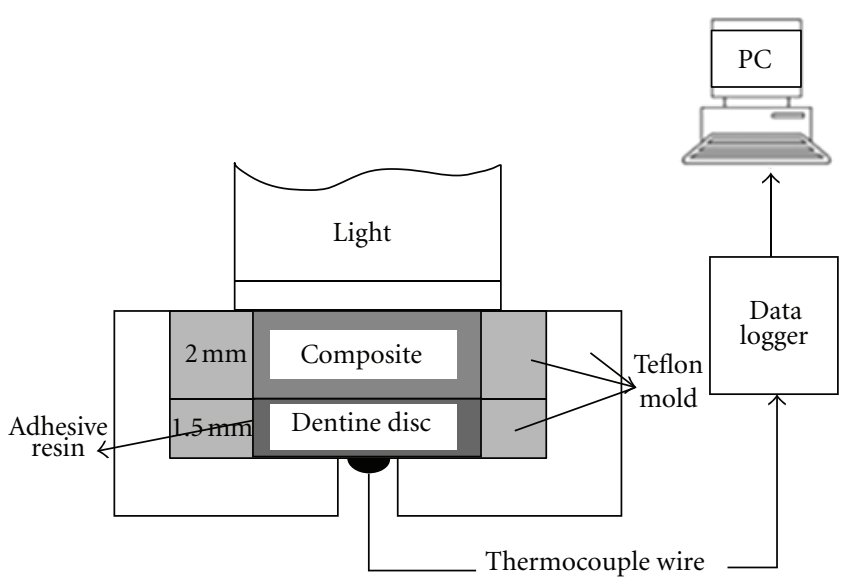

Figure 2: Schematic view of the temperature rise measurement during polymerization of the materials under the dentin discs.

procedures was adjusted on a low intensity of $500 \mathrm{~mW} / \mathrm{cm}^{2}$. Subsequent to light output evaluation, the test was repeated for 10 dentin samples in each group (Figure 1). The difference between the baseline temperature and the highest temperature recorded was calculated and registered. Temperature means and standard deviations were obtained for each material with demineralized and undemineralized dentin samples. There were ten samples in each group. Data was analyzed using SPSS software Ver. 13.5. Statistical significance was defined at $\alpha=0.05$. Data were analyzed by repeated measures ANOVA. Paired sample $t$-test was used to evaluate differences between the study groups.

\section{Results}

Table 2 presents temperature variation means during the photopolymerization procedures of the 6 study groups. Table 2, and Figures 3 and 4 present temperature fluctuations during each photopolymerization step of LS primer, LS adhesive and LS composite resin beneath the undemineralized and demineralized dentin samples, respectively.

The mean temperature rise values during photopolymerization for $10 \mathrm{~s}$ beneath undemineralized and demineralized dentin samples without any material (groups 1) were $2.39 \pm$ $0.60^{\circ} \mathrm{C}$ and $2.47 \pm 0.40^{\circ} \mathrm{C}$, respectively. The mean temperature rise values during photopolymerization for $40 \mathrm{~s}$ were $6.26 \pm 1.10^{\circ} \mathrm{C}$ and $7.02 \pm 0.43^{\circ} \mathrm{C}$ with undemineralized and demineralized dentin samples, respectively. There were no significant differences in temperature rise means between the two dentin disc samples for each irradiation duration $(P>$ 0.05). However, significant differences were revealed between the two irradiation durations $(P<0.0001)$ (Table 2). On the other hand, ANOVA and paired $t$-test, which were used to determine differences in temperature rise between the groups within the materials and durations, showed that all temperature rise values measured with $40 \mathrm{~s}$ duration were significantly higher than those of $10 \mathrm{~s}$ duration for both undemineralized and demineralized dentin samples $(P<$ 0.0001) (Table 2).

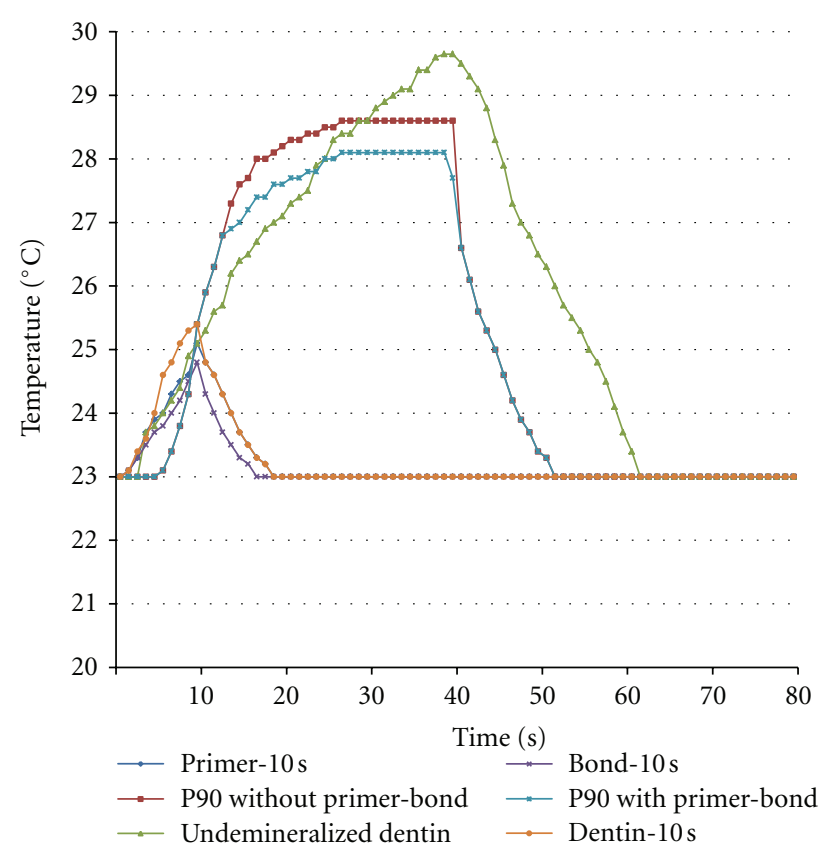

FIGURE 3: Temperature changes during primer, adhesive, and composite resin photopolymerization of silorane-based low-shrinkage composite under undemineralized dentin.

Although the mean of temperature rise during $40 \mathrm{~s}$ lightcuring procedure of Filtek LS without primer and adhesive (groups 6) was higher than that in group 5, in which 2-mmthick Filtek LS was applied subsequent to the application and curing of primer and adhesive according to the manufacturer's instructions, there were no significant differences between the groups above under both undemineralized and demineralized dentin $(P>0.05)$. The maximum temperature rise was recorded during photopolymerization of Filtek P90 under demineralized dentin samples without application and curing of primer and adhesive (6.25 \pm $1.02^{\circ} \mathrm{C}$ ), followed by that recorded in the corresponding group with undemineralized dentin sample $\left(5.58 \pm 0.86^{\circ} \mathrm{C}\right)$.

\section{Discussion}

Photopolymerization of dental adhesives and resin-based composite resins increases dentin temperature through exothermic resin polymerization process and the energy absorbed during light-curing. The rate of exothermic polymerization reaction and maximum temperature rise during the process is proportional to the irradiance of the lightcuring unit, chemical structure of the adhesive, and/or the composite resin and the light conduction properties of composite resin [27-29].

Although dentin has a low thermal conductivity, the risk of pulp damage is high in deep composite restorations because dentinal tubules are more numerous and denser in deep cavities. As a result, irritation of the pulp due to heat depends on the extent and duration of temperature rise [3032]. 
TABLE 2: Temperature rise values (mean $\pm \mathrm{SD})$ during photopolymerization under demineralized and undemineralized dentin disks $(n=$ $10)$.

\begin{tabular}{|c|c|c|c|}
\hline \multirow{2}{*}{ Groups } & \multirow{2}{*}{ Groups definitions } & \multicolumn{2}{|c|}{ Mean $\pm \mathrm{SD}\left({ }^{\circ} \mathrm{C}\right)$} \\
\hline & & Undemineralized dentin & Demineralized dentin \\
\hline 1 & $\Delta T$ Dentin (10 s light curing) & $2.39 \pm 0.60^{\mathrm{aA}}$ & $2.47 \pm 0.40^{\mathrm{aA}}$ \\
\hline 2 & $\Delta T$ Dentin (40 s light curing) & $6.26 \pm 1.10^{\mathrm{aB}}$ & $7.02 \pm 0.43^{\mathrm{aB}}$ \\
\hline 3 & $\Delta T$ LS System adhesive primer (10 s light curing) & $2.14 \pm 0.31^{\mathrm{aA}}$ & $2.34 \pm 0.27^{\mathrm{aA}}$ \\
\hline 4 & $\Delta T$ LS System adhesive bond (10 s light curing) & $1.83 \pm 0.17^{\mathrm{aA}}$ & $1.98 \pm 0.24^{\mathrm{aA}}$ \\
\hline 5 & $\Delta T$ Filtek LS with primer and adhesive (40 s light curing) & $5.14 \pm 0.62^{\mathrm{aB}}$ & $5.45 \pm 0.49^{\mathrm{aB}}$ \\
\hline 6 & $\Delta T$ Filtek LS without primer and adhesive (40 s light curing) & $5.58 \pm 0.86^{\mathrm{aB}}$ & $6.25 \pm 1.02^{\mathrm{aB}}$ \\
\hline
\end{tabular}

Means followed by different letters show statistical differences: $(\alpha=0.05)$.

Lower case letters: comparison of dentin discs at each procedure (row).

Capital letters: comparison of each photopolymerization step for each kind of dentin (column).

$\Delta T$ : temperature change.

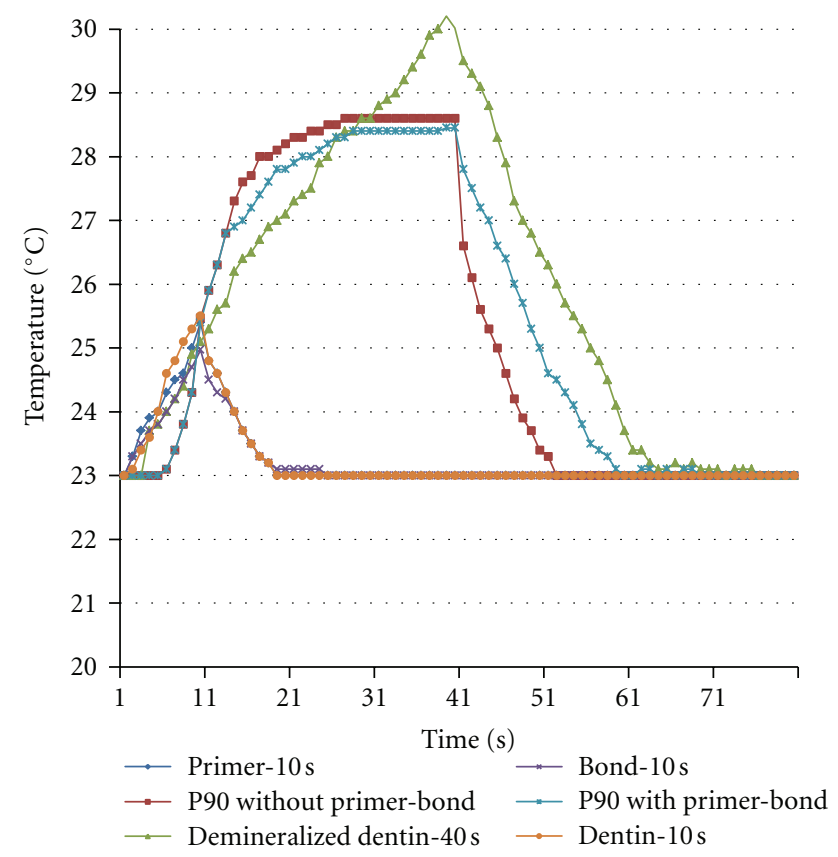

Figure 4: Temperature changes during primer, adhesive, and composite photopolymerization of silorane-based low-shrinkage composite under demineralized dentin.

The results of the present study in relation to the comparison of groups 1 and 2, in which only sound and demineralized dentin samples without any changes were irradiated, showed that a $10 \mathrm{~s}$ irradiation (group 1) resulted in a temperature rise of $2.39^{\circ} \mathrm{C}$ and $2.47^{\circ} \mathrm{C}$ in undemineralized and demineralized dentin samples, respectively; a $40 \mathrm{~s}$ irradiation (group 2) increased dentin sample temperatures up to $6.26^{\circ} \mathrm{C}$ and $7.02^{\circ} \mathrm{C}$, respectively, demonstrating statistically significant differences between the two groups.

Based on the results of several studies [29-33], the irradiation intensity and the duration of curing are the most important factors influencing temperature fluctuations, consistent with the results of the present study.

There is consensus that temperature rise due to certain dental procedures threatens pulp vitality [34]. It has also been postulated that visible light polymerization units might increase temperatures within the pulp chamber, irritating the pulp [35]. In the present study, in groups 3 to 5, Filtek P90 composite resin was applied by exactly following the manufacturer's instructions, that is, in each of the steps involving the application of primer, adhesive, and the LS composite resin the temperature rise was accurately measured through normal and demineralized dentin.

An animal study by Zach and Cohen resulted in determination of a threshold temperature for irreversible pulp injury during application of external heat to a sound tooth: a $5.5^{\circ} \mathrm{C}$ intrapulpal temperature rise gave rise to necrosis in $15 \%$ of the pulps [10].

In this in vitro study temperature variations were evaluated under demineralized and undemineralized dentin samples during the photopolymerization of primer, adhesive and composite resin of a low-shrinkage silorane system using an LED light-curing unit. The numeric values of temperature rise after photopolymerization of each material-primer, adhesive and silorane-based composite resin-were higher with demineralized dentin compared to normal dentin samples; however, the mean values were near the threshold only during photopolymerization of the LS composite resin for $40 \mathrm{~s}$.

Previous studies have shown that the extent of temperature depends on two factors: the exothermic polymerization reaction of composite resin during photopolymerization and the energy output of the light-curing unit [36-38]. The results of the present study supported the hypothesis that longer photopolymerization times result in significantly greater temperature rise compared to shorter irradiation times.

It has already been reported in relation to conventional methacrylate-based composite resins that the temperature rise decreases as the resin filler content of a dental material increase because less resin is available for polymerization. Fillers are chemically inert and do not contribute to an increase in the heat of reaction. However, filler temperature increases along with that of the matrix. Therefore, a considerable proportion of the energy which might otherwise increase the temperature of the resin matrix is absorbed 
and dissipated by the filler. In this context, fillers are active phases with a moderate role $[32,38]$.

A silorane-based resin composite has recently been introduced. The term "silorane" is derived from its chemical composition of siloxanes and oxiranes [39]. The combined properties of siloxanes and oxiranes result in a composite resin which is claimed to be biocompatible, hydrophobic and low-shrinkage [39]. The new resin matrix has a specific twopart self-etching primer adhesive. The primer component of the adhesive consists of hydrophilic methacrylate-based resins similar to those of other adhesive systems [39]; however, the hydrophobic adhesive bond, which has specially been designed to achieve compatibility with the newly developed silorane restorative resin [39], has been claimed to have lower polymerization stress and shrinkage.

Based on manufacturer's recommendations, the primer, the adhesive and the composite resin should be cured for 10, 10 and $40 \mathrm{~s}$, respectively [23]. Groups 3 to 5 were designed for each of the procedural steps of material application for more accurate evaluation of temperature variations through normal and demineralized dentin samples. Based on the results, LS primer/adhesive and LS restorative material exhibited different maximum temperature rise values, with statistically significant differences, which might be attributed to differences in polymerization times ( $10 \mathrm{~s}$ versus $40 \mathrm{~s}$ ) and also to differences in resin contents.

A number of previous studies have shown that adhesive resins, which are unfilled materials, exhibit greater temperature variations compared to resin-containing restorative materials [28, 38]. Comparison of groups 3 and 4 with group 1 in the present study showed a slight protective effect of the adhesive layer. It should also be pointed out that adhesive resins absorb heat energy during photopolymerization as they confer thermal insulation to the underlying dentin and pulpal tissue during the process [28].

In the present study, the mean temperature rises were recorded during photopolymerization of LS primer $\left(2.34^{\circ} \mathrm{C}\right)$, LS Bond $\left(1.98^{\circ} \mathrm{C}\right)$ and Filtek LS composite $\left(5.45^{\circ} \mathrm{C}\right)$ beneath demineralized dentin samples. The values for the primer and adhesive were much lower than the temperature threshold for irreversible pulp injury; however, it was near the threshold for Filtek LS composite resin. Fortunately, temperatures are modified by the circulation in the pulp chamber and fluid movements in dentinal tubules in clinical situations $[22,30]$. Moreover, periodontal tissues can dissipate heat in vivo, further decreasing intrapulpal temperature [22]. Therefore, the hypothesis of the study was confirmed for the LS self-etch primer (P) and adhesive (A) systems and was rejected for the silorane-based composite resin system (P90) because the highest values of temperature rise during photopolymerization of the LS system was recorded in groups 5 and 6 , especially with the demineralized dentin, in which irradiation duration was $40 \mathrm{~s}$, which was near the critical threshold value.

This observation is consistent with the results of studies by Shortall and Harrington [40] and da Silva et al. [38] concluding that the light attenuating ability of the material exceeds the effect of exothermic polymerization reaction at the base of the cavity floor. Although dentin has a relatively low thermal conductivity, there is a higher risk for pulp injury in deep cavities in which there is a thin layer of residual dentin, with increased permeability of dentin tubules. Knezevic et al. [36] reported that the temperature rise increases as the material's thickness decreases.

Based on the results of a study by Lloyd and Brown [34], the rate of exothermic photopolymerization reaction is directly proportional to the inorganic content of composite resin. Therefore, as the inorganic content decreases, the organic content increases and as a result, the exothermic reaction is stronger. The results of the present study showed that the Filtek LS composite resin without LS primer and/or LS adhesive (G5) was not statistically different in temperature change from the same composite resin with LS primer and LS adhesive due to similar content, thickness, and curing protocol.

In the present study, temperature rise was higher in the primer compared to the adhesive after photopolymerization. It appears the light-cured primer plays the role of an insulating layer for the heat produced as a result of photopolymerization of the adhesive layer to some extent. In this context, comparison of groups 5 and 6 showed the effect of light-cured primer and adhesive layers on the decrease of heat transfer through both types of dentin with LS composite resin. It appears the light-cured primer and adhesive layers function as an insulating layer for the heat generated as a result of photopolymerization of composite resin. Evaluation of temperature changes during polymerization of each LS system layer (Figures 3 and 4) confirm the mean results achieved.

Previously, Miletic et al. showed that if the light output energy during photopolymerization remains constant for all resin-based composite resins, including silorane-based composite resin, a substantially different heat generation pattern would be observed with Filtek LS, which might be attributed to a different photopolymerization reaction. Filtek LS is a siloxane- and oxirane-based composite resin, which polymerizes through a cationic ring-opening reaction [28]. This reaction takes place in the oxirane component and is initiated by a photochemical reaction during which camphorquinone excited by light energy, interacts with iodonium salts and electron donors to yield cations as propagating active centers. In brief, in the present study comparison of groups 5 and 6 showed the effect of lightcured primer and adhesive layers on a decrease in light conductivity through both types of dentin [28].

In the present study an LED light-curing unit with low intensity mode of $550 \mathrm{~mW} / \mathrm{cm}^{2}$ was used. Some studies [28, 38] have shown that QTH units with higher light intensities result in more temperature variations with dimethacrylatebased composite resins [32]; in this context, future studies should investigate low-shrinkage composite resins. Although the present study showed mean temperature rises of $5.58^{\circ} \mathrm{C}$ and $6.25^{\circ} \mathrm{C}$ under the undemineralized and demineralized dentin, respectively, it can be suggested that this range of temperature rise might induce pulp injury because it has been reported that a temperature rise in the order of $5.5^{\circ} \mathrm{C}$ during photopolymerization of dental restorative materials is the threshold to avoid irreversible changes 
in the pulp [10]. However, some other studies have shown that even higher temperature rises cannot induce irreversible pulp damage [41]. Therefore, there is controversy over the critical temperature threshold beyond which irreversible pulp damage occurs; however, it can be recommended that the pulp temperature should be kept as low as possible during composite resin photopolymerization to avoid any irreversible pulp injury [38].

Comparison of temperature changes in different groups of the present study, particularly in the presence of demineralized dentin, which is very similar to clinical situations, shows that dental practitioners should be aware of the risk of thermal insults to the pulp as a result of photopolymerization of resin-containing restorative materials, especially when caries-affected deep dentin is involved for longer periods. In such conditions, a simple but very effective method for pulp protection is to use an effective cement base or lining material to reduce the intrapulpal temperature rise during light polymerization of composite resin [22].

\section{Conclusions}

Within the limitations of this in vitro study, the following conclusions were drawn.

40 s light-curing of Filtek LS exhibited a significantly different heat generation mode and significantly greater temperature variations beneath $1.5 \mathrm{~mm}$ thick samples of demineralized and undemineralized dentin samples compared to 10 s light-curing of each of the LS primer and adhesive. Lightcured self-etching LS system primer/adhesive functions as a heat insulation layer during photopolymerization of the Filtek LS restorative material.

The structural differences between undemineralized and demineralized dentin samples did not significantly influence temperature rise during photopolymerization of the lowshrinkage composite resin under study.

There were no significant differences between the temperature rises as a result of photopolymerization of the LS system self-etch adhesive primer/adhesive under demineralized and undemineralized dentin samples.

Temperature rise during photopolymerization of Filtek LS restorative material exceeded $5.5^{\circ} \mathrm{C}$ under demineralized dentin samples, which should be evaluated in future studies.

\section{Conflict of Interests}

The authors declare that they have no conflict of interests.

\section{Authors' Contribution}

S. M. Mousavinasab and M. Khoroushi have similar contributions in this research.

\section{Acknowledgments}

This study was conducted through an Institutional University Research Grant, financially supported and approved by
Isfahan University of Medical Sciences, Isfahan, Iran (no. 390343).

\section{References}

[1] C. H. Lloyd, A. Joshi, and E. McGlynn, "Temperature rises produced by light sources and composites during curing," Dental Materials, vol. 2, no. 4, pp. 170-174, 1986.

[2] S. Masutani, J. C. Setcos, R. J. Schnell, and R. W. Phillips, "Temperature rise during polymerization of visible lightactivated composite resins," Dental Materials, vol. 4, no. 4, pp. 174-178, 1988.

[3] M. Hannig and B. Bott, "In-vitro pulp chamber temperature rise during composite resin polymerization with various lightcuring sources," Dental Materials, vol. 15, no. 4, pp. 275-281, 1999.

[4] D. S. Cobb, D. N. Dederich, and T. V. Gardner, "In vitro temperature change at the dentin/pulpal interface by using conventional visible light versus argon laser," Lasers in Surgery and Medicine, vol. 26, no. 4, pp. 386-397, 2000.

[5] A. Knežević, Z. Tarle, A. Meniga, J. Šutalo, G. Pichler, and M. Ristić, "Degree of Conversion and temperature rise during polymerization of composite resin samples with blue diodes," Journal of Oral Rehabilitation, vol. 28, no. 6, pp. 586-591, 2001.

[6] L. F. Schneider, S. Consani, L. Correr-Sobrinho, A. B. Correr, and M. A. Sinhoreti, "Halogen and LED light curing of composite: temperature increase and Knoop hardness," Clinical Oral Investigations, vol. 10, no. 1, pp. 66-71, 2006.

[7] A. R. Yazici, A. Müftü, G. Kugel, and R. D. Perry, "Comparison of temperature changes in the pulp chamber induced by various light curing units, in vitro," Operative Dentistry, vol. 31, no. 2, pp. 261-265, 2006.

[8] H. E. Goodis, J. M. White, J. Andrews, and L. G. Watanabe, "Measurement of temperature generated by visible-light-cure lamps in an in vitro model," Dental Materials, vol. 5, no. 4, pp. 230-234, 1989.

[9] D. F. Murchison and B. K. Moore, "Influence of curing time and distance on microhardness of eight light-cured liners," Operative Dentistry, vol. 17, no. 4, pp. 135-141, 1992.

[10] L. Zach and G. Cohen, "Pulp response to externally applied heat," Oral Surgery, Oral Medicine, Oral Pathology, vol. 19, no. 4, pp. 515-530, 1965.

[11] P. Baldissara, S. Catapano, and R. Scotti, "Clinical and histological evaluation of thermal injury thresholds in human teeth: a preliminary study," Journal of Oral Rehabilitation, vol. 24, no. 11, pp. 791-801, 1997.

[12] D. A. Stewardson, A. C. C. Shortall, E. Harrington, and P. J. Lumley, "Thermal changes and cure depths associated with a high intensity light activation unit," Journal of Dentistry, vol. 32, no. 8, pp. 643-651, 2004.

[13] A. A. Al-Qudah, C. A. Mitchell, P. A. Biagioni, and D. L. Hussey, "Thermographic investigation of contemporary resincontaining dental materials," Journal of Dentistry, vol. 33, no. 7, pp. 593-602, 2005.

[14] F. H. Loureiro, S. Consani, R. D. Guiraldo et al., "Comparison between two methods to evaluate temperature changes produced by composite light curing units and polymerization techniques," Minerva Stomatologica, vol. 60, no. 10, pp. 501508, 2011.

[15] R. W. Loney and R. B. Price, "Temperature transmission of high-output light-curing units through dentin," Operative Dentistry, vol. 26, no. 5, pp. 516-520, 2001. 
[16] L. F. J. Schneider, S. Consani, M. A. C. Sinhoreti, L. Correr Sobrinho, and F. M. Milan, "Temperature change and hardness with different resin composites and photo-activation methods," Operative Dentistry, vol. 30, no. 4, pp. 516-521, 2005.

[17] D. H. Pashley, "Clinical correlations of dentin structure and function," The Journal of Prosthetic Dentistry, vol. 66, no. 6, pp. 777-781, 1991.

[18] M. Nakajima, M. Ogata, M. Okuda, J. Tagami, H. Sano, and D. H. Pashley, "Bonding to caries-affected dentin using selfetching primers," American Journal of Dentistry, vol. 12, pp. 309-314, 1999.

[19] M. Nakajima, H. Sano, M. F. Burrow et al., "Tensile bond strength and SEM evaluation of caries-affected dentin using dentin adhesives," Journal of Dental Research, vol. 74, no. 10, pp. 1679-1688, 1995.

[20] M. Nakajima, Y. Kitasako, M. Okuda, R. M. Foxton, and J. Tagami, "Elemental distributions and microtensile bond strength of the adhesive interface to normal and caries-affected dentin," Journal of Biomedical Materials Research_Part B, vol. 72, no. 2, pp. 268-275, 2005.

[21] K. B. Fanbunda and A. De Sa, "Thermal conductivity of normal and abnormal human dentine," Archives of Oral Biology, vol. 20, no. 7, pp. 457-459, 1975.

[22] G. Tosun, A. Usumez, I. Yondem, and Y. Sener, "Temperature rise under normal and caries-affected primary tooth dentin disks during polymerization of adhesives and resin-containing dental materials," Dental Materials Journal, vol. 27, no. 3, pp. 466-470, 2008.

[23] 3M-ESPE. Filtek Silorane Low Shrinkage Posterior Restorative, Silorane System Adhesive Self-Etch Primer and Bond 3MESPE, Seefeld, Germany, 2007.

[24] J. V. Crivello, B. Falk, and M. R. Zonca Jr., "Photoinduced cationic ring-opening frontal polymerizations of oxetanes and oxiranes," Journal of Polymer Science, Part A, vol. 42, no. 7, pp. 1630-1646, 2004.

[25] T. Fu, H. Zhao, J. Zeng, M. Zhong, and C. Shi, "Two-color optical charge-coupled-device-based pyrometer using a twopeak filter," Review of Scientific Instruments, vol. 81, no. 12, Article ID 124903, 2010.

[26] B. Yang, G. Flaim, and S. H. Dickens, "Remineralization of human natural caries and artificial caries-like lesions with an experimental whisker-reinforced ART composite," Acta Biomaterialia, vol. 7, no. 5, pp. 2303-2309, 2011.

[27] A. Pereira Da Silva, L. Alves Da Cunha, C. Pagani, and S. De Mello Rode, "Temperature rise during adhesive and composite polymerization with different light-curing sources," Minerva Stomatologica, vol. 59, no. 5, pp. 253-258, 2010.

[28] V. Miletic, V. Ivanovic, B. Dzeletovic, and M. Lezaja, “Temperature changes in silorane-, ormocer-, and dimethacrylatebased composites and pulp chamber roof during light-curing," Journal of Esthetic and Restorative Dentistry, vol. 21, no. 2, pp. 122-131, 2009.

[29] B. Ozturk, A. N. Ozturk, A. Usumez, S. Usumez, and F. Özer, "Temperature rise during adhesive and resin composite polymerization with various light curing sources," Operative Dentistry, vol. 29, no. 3, pp. 325-332, 2004.

[30] J. Leprince, J. Devaux, T. Mullier, J. Vreven, and G. Leloup, "Pulpal-temperature rise and polymerization efficiency of LED curing lights," Operative Dentistry, vol. 35, no. 2, pp. 220230, 2010.

[31] M. B. Jakubinek, C. O’Neill, C. Felix, R. B. Price, and M. A. White, "Temperature excursions at the pulp-dentin junction during the curing of light-activated dental restorations," Dental Materials, vol. 24, no. 11, pp. 1468-1476, 2008.

[32] M. Atai and F. Motevasselian, "Temperature rise and degree of photopolymerization conversion of nanocomposites and conventional dental composites," Clinical Oral Investigations, vol. 13, no. 3, pp. 309-316, 2009.

[33] N. Meredith, A. Watts, R. C. Patterson, and R. Strang, "Investigation of the temperature rise produced in the pulp chamber by operative procedures," Journal of Dental Research, vol. 63, no. 4, article 511, 1984, abstract no. 193.

[34] C. H. Lloyd and E. A. Brown, "The heats of reaction and temperature rises associated with the setting of bonding resins," Journal of Oral Rehabilitation, vol. 11, no. 4, pp. 319-324, 1984.

[35] N. M. Taher, Y. Al-Khairallah, S. H. Al-Aujan, and M. Ad'dahash, "The effect of different light-curing methods on temperature changes of dual polymerizing agents cemented to human dentin," Journal of Contemporary Dental Practice, vol. 9, no. 2, pp. 57-64, 2008.

[36] A. Knezevic, K. Sariri, I. Sovic, N. Demoli, and Z. Tarle, "Shrinkage evaluation of composite polymerized with LED units using laser interferometry," Quintessence International, vol. 41, no. 5, pp. 417-425, 2010.

[37] A. Melara Munguía, M. Arregui Gambús, F. Guinot Jimeno, and L. J. Bellet Dalmau, "Temperature changes caused by light curing units on dentine of primary teeth," European Journal of Paediatric Dentistry, vol. 12, no. 1, pp. 7-12, 2011.

[38] E. M. da Silva, A. G. Penelas, M. S. Simão, J. D. N. Filho, L. T. Poskus, and J. G. A. Guimarães, "Influence of the degree of dentine mineralization on pulp chamber temperature increase during resin-based composite (RBC) light-activation," Journal of Dentistry, vol. 38, no. 4, pp. 336-342, 2010.

[39] O. A. Adebayo, M. F. Burrow, M. J. Tyas, and J. Palamara, "Effect of tooth surface preparation on the bonding of selfetching primer adhesives," Operative Dentistry, vol. 37, no. 2, pp. 137-149, 2012.

[40] A. C. Shortall and E. Harrington, "Temperature rise during polymerization of light-activated resin composites," Journal of Oral Rehabilitation, vol. 25, no. 12, pp. 908-913, 1998.

[41] A. Uhl, R. W. Mills, A. E. Rzanny, and K. D. Jandt, "Time dependence of composite shrinkage using halogen and LED light curing," Dental Materials, vol. 21, no. 3, pp. 278-286, 2005. 


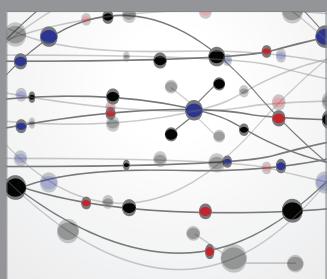

The Scientific World Journal
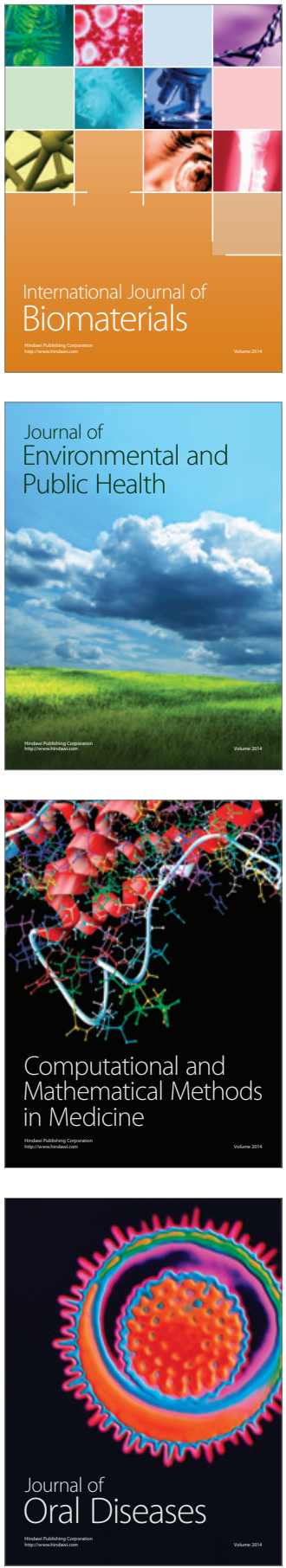
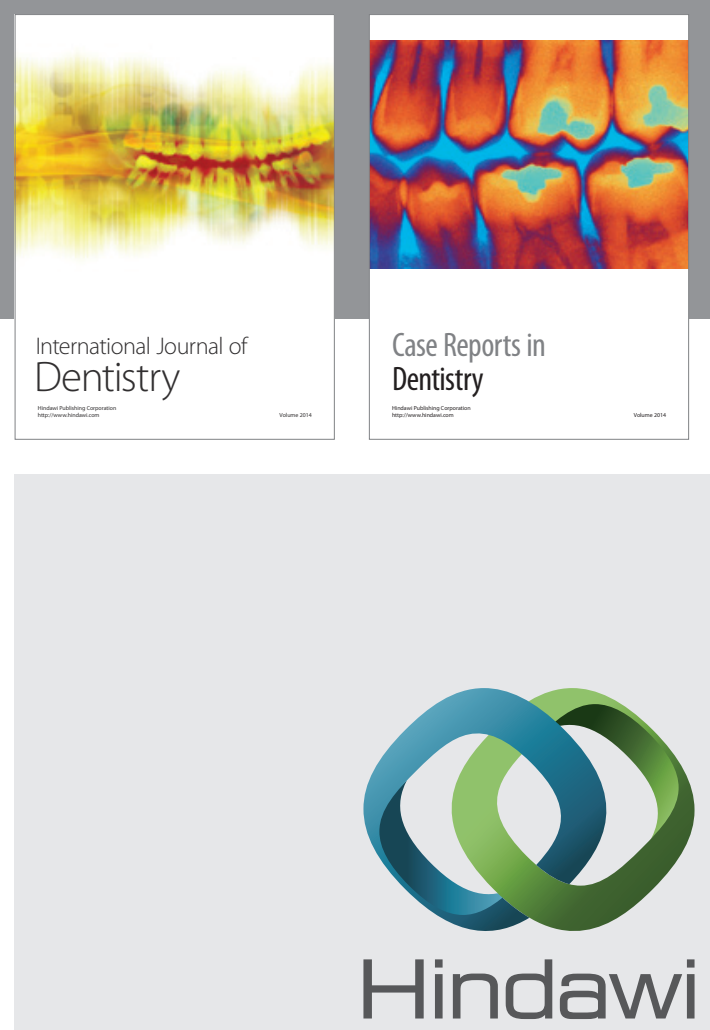

Submit your manuscripts at

http://www.hindawi.com
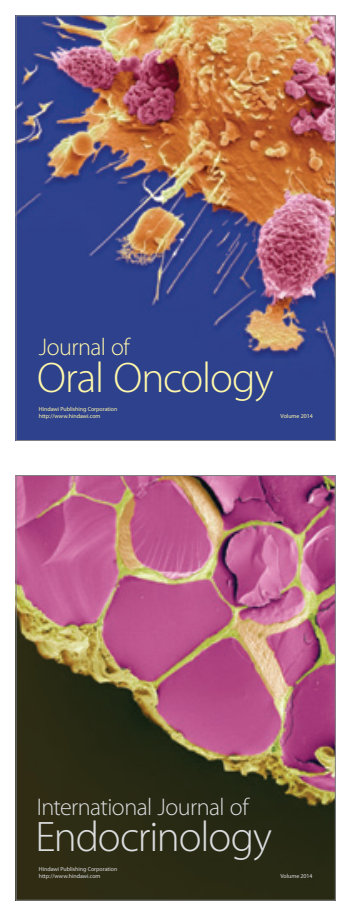
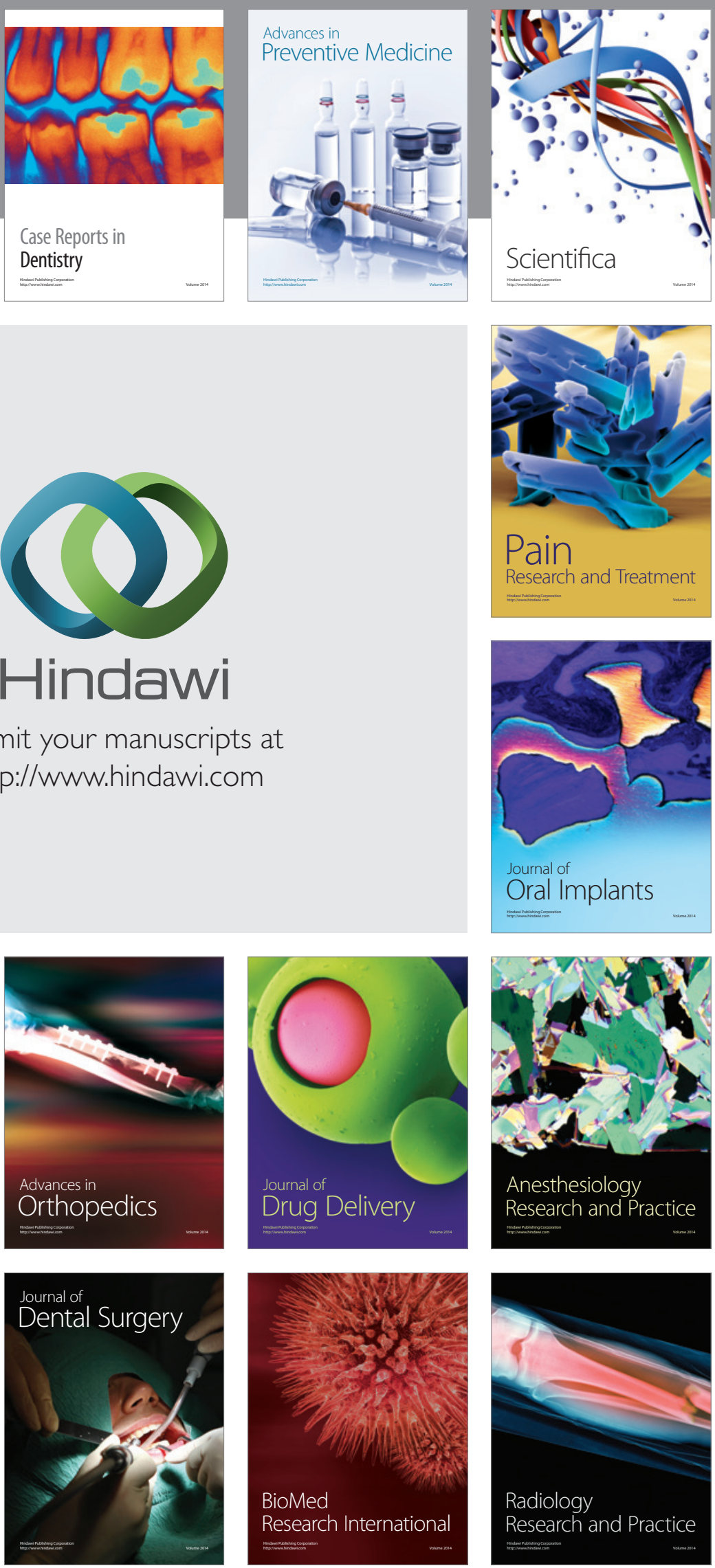